\title{
CONFORMACIÓN DEL PODER JUDICIAL EN COLOMBIA A PARTIR DE LAS CONSTITUCIONES PROVINCIALES COMPRENDIDAS EN EL PERIODO DE 1810-1821*
}

\author{
Omar Antonio Herrán Pinzón **
}

Fecha de Recepción: 17 de marzo de 2011

Fecha de Aceptación: 13 de abril de 2011

Artículo resultado de Proyecto de Investigación

\begin{abstract}
Resumen
El contenido de las diversas Constituciones en el período comprendido entre 1810-1821, se sintetiza en las circunstancias que ha vivido el pueblo Colombiano en el desarrollo constitucional del poder judicial en Colombia. Si se afirmase que no es posible una democracia sin un poder judicial democrático donde éste vele por el respeto de las libertades de los individuos en forma tal; el Estado tendría la obligación de proteger y respetar la organización estatal en la división de poderes como un proyecto jurídico - político en desarrollo en las constituciones provinciales. Es decir, si no hay una estructura institucional que permita el ejercicio judicial de la solución de conflictos en forma autónoma e independiente, se terminaría en un mero enunciado institucional.
\end{abstract}

\section{Palabras clave}

Instituciones coloniales, poder judicial, constituciones provinciales

\section{FORMATION OF THE JUDICIARY FROM THE COLOMBIAN CONSTITUTION PROVINCIAL IN THE PERIOD FROM 1810 TO 1821}

\begin{abstract}
What various constitutions in the period from 1810 to 1821 contain is synthesized in the circumstances under Colombian people have lived in the constitutional development of the judicial power in this country. If on believe that democracy can not exist without a democratic judicial power, where the respect to individual liberties is sure, in the way the state is obligated to protect and respect the state organization in the power division as a legal - politic development Project on provincial constitutions well said if there is not an institutional structure that allowed the judicial exercise of conflicts resolution in an autonomous and independent way we were talking only about an institutional statement.
\end{abstract}

* Este artículo es resultado de la investigación denominada Conformación del Poder Judicial Colombiano a Partir de las Constituciones Provinciales, Corresponde a un producto académico de la línea "Historia del Derecho Administrativo en Colombia", del grupo "Derecho Público", categoría B - COLCIENCIAS, de la Facultad de Derecho de la Universidad Militar Nueva Granada del proyecto "El Proceso Político y Jurídico Independentista en Colombia, México y Brasil.

** Abogado de la Universidad Militar Nueva Granada, Maestrante en Derecho Procesal Penal de la misma Universidad. La actividad investigativa se desarrolla dentro del programa de "Jóvenes Investigadores" que respalda COLCIENCIAS a las Instituciones de Educación Superior en Colombia, asignado para su formación a la investigadora y docente JACQUELINE BLANCO BLANCO. omar.herran@unimilitar.edu.co 


\title{
Key words
}

Colonial institutions, the judiciary, provincial constitutions

\section{CONFORMAÇÃO DO PODER JUDICIÁRIO NA COLÔMBIA A PARTIR DAS CONSTITUIÇÕES PROVINCIAISCOMPREENDIDAS NO PERÍODO DE 1810 A 1821}

\begin{abstract}
Resumo
O conteúdo das diversas Constituições, no período compreendido entre 1810 e 1821, é sintetizado nas circunstâncias vividas pelo povo Colombiano na evolução constitucional do Poder Judiciário na Colômbia. Se afirmado que não é possível uma democracia sem um poder judiciário democrático que vele pelo respeito às liberdades dos indivíduos, o Estado teria a obrigação de proteger e respeitar a organização estatal na divisão de poderes como um projeto jurídico-político em desenvolvimento nas constituições provinciais. Isto significa que, não havendo uma estrutura institucional que permita o exercício judiciário na solução de conflitos de forma autônoma e independente, acabaria sendo um mero enunciado institucional.
\end{abstract}

\section{Palavras-chave}

Instituições coloniais, poder judicial, constituições provinciais.

\section{INTRODUCCIÓN}

La base de los regímenes democráticos no es la decisión mayoritaria de sus ciudadanos, sino el gobierno limitado a unos pocos que colocan en sus agendas políticas el devenir del Estado; por lo tanto, la desconcentración de la administración del poder y la separación funcional de los órganos del Estado tiene como fundamento la necesidad de garantizar que los individuos no serán sometidos de forma arbitraria a las ideas de un régimen anacrónico y opresor como lo era la monarquía. Se pretendía una democracia basada en la garantía de derechos individuales la independencia en la administración de los poderes y el respeto a las diferencias, bajo la concepción del derecho a la igualdad de todos ante la ley.

Las ideas de la Revolución Francesa tuvieron una huella parcial en las Colonias Americanas, el postulado de igualdad entre todos los hombres no era compatible con los intereses económicos de la clase autóctona dominante, ya que esta igualdad sólo se pregona entre los miembros de su propia clase pero no entre los indios, negros y mestizos entre otros; sino una que protegiera los derechos y garantías de la nueva clase dominante. No obstante, la república es una evolución de los regímenes políticos con esquema monárquico, donde el rey no sólo gobierna sino que también dispone, legisla y juzga.

El presente trabajo es un resultado del proyecto de investigación "El Proceso Político y Jurídico Independentista en Colombia, México y Brasil", coordinado por la doctora Jacqueline Blanco Blanco. Los resultados investigativos muestran como el poder judicial en el período comprendido entre 1810 y 1821 fue una herramienta institucional que permitió controlar las ideas políticas, sociales, jurídicas y económicas debido al poco grado de autonomía que este órgano tenía con relación al poder ejecutivo y legislativo.

El objetivo principal del presente artículo es demostrar cómo el poder judicial tiene su causa en las instituciones copiadas de Estados Unidos y Eu- 
ropa, generalmente modificadas por sus dirigentes marcadas por intereses sectoriales y corporativos cercanos de los constituyentes y legisladores de turno creándose Tribunales análogos a España en tiempos de la colonia y con posterioridad a la independencia. La doctora Jacqueline Blanco Blanco en su libro Historia y administración del Estado Colombiano expresa que el gobierno republicano colombiano fue "una república al mejor estilo Europeo" bajo la hipótesis de que la efectividad de los derechos a la igualdad, libertad y legalidad nacen del Estado de Derecho como consecuencia necesaria de control y ejercicio del poder, tema que aparece referenciado en las constituciones provinciales como agenda sine qua non para la existencia de una democracia.

La metodología que se ha utilizado en el presente escrito es el método hermenéutico se hace un análisis normativo de la temática descrita; para poder precisar la evolución del poder judicial en Colombia. No faltan los argumentos críticos acerca de la independencia en el entendido que sólo existe en el papel que se trata de un ente significativo, que no es en realidad independiente de las otras ramas del poder público.

\section{ANTECEDENTES}

Durante la Colonia se establecieron algunas Instituciones para implantar un nuevo orden territorial que buscara la protección de los indios, por ejemplo las Reales Audiencias se constituyeron como tribunales con funciones políticas, administrativas y judiciales tratando de limitar el poder de los colonizadores. Las injusticias que se daban en la Colonia gestaban una tendencia revolucionaria dentro de los movimientos que nacían de las ideas de la Ilustración; la Revolución Francesa y el Liberalismo dieron el último impulso a la emancipación de las colonias americanas, aspiración latente entre los próceres que pretendía dar cuenta de la inobservancia del derecho visible en el período de transición hacia la independencia.

Tras la unificación de los reinos de Castilla y Aragón, las guerras que dieron paso a esta unificación trajeron consigo una crisis eco- nómica en España, los reyes establecieron una organización político administrativa que garantizaba el control y supervisión de los territorios conquistados con el objetivo de suplir las necesidades de los conquistadores.

Las ideas revolucionarias de los angloamericanos y franceses de mediados y finales del siglo XVIII, (TASCON: 2000: 9) trajeron consigo la unión de tradición jurídica española junto con las ideas revolucionarias del establecimiento de un Estado de Derecho mediante la expedición de un ordenamiento Constitucional que contemplaba de manera expresa la forma de gobierno republicano y democrático, garantías sociales y derechos civiles de contenido netamente individualista. Contrastaba con el derecho metropolitano español arraigado en los territorios coloniales, contenido en documentos como el Código de Castilla y León promulgado por Alfonso XI conocido como el Ordenamiento de Alcalá 1384, (PACHECO, DE LA PUENTE \& APEZECHEA: 1847: 443) las leyes de Toro de 1505, (LLAMAS: 1827: 8) nueva recopilación de Castilla de 1567, Novísima recopilación de Castilla de 1805, normas de derecho romano y canónico contenidas en las Siete Partidas de Alfonso X y, finalmente las normas formuladas de manera específica para los territorios coloniales impuestos por Felipe II que dieron origen a la recopilación de las leyes de Indias de 1680 conformando un orden legal específico en América. (GARCÍA: 1954) La reglamentación española de indias confesaba a la conversión y civilización de los indígenas fin primordial del Estado español por consiguiente se pretendía la concepción de un Estado católico, es decir, una organización política al servicio de la salvación de las almas. (TUDELA: 1954: 353) Las ordenanzas de poblaciones de 1573 declara Felipe II. "El fin que nos mueve a hacer nuevos descubrimientos es la predicación de la Santa Fe Católica, y que los indios sean enseñados y vivan en paz". (TUDELA: 1954: 353)

\subsection{Instituciones de la Colonia}

En el orden central se encontraba el Consejo Superior de Indias, conformado por un presidente y 
un grupo de funcionarios tales como: fiscales, relatores, secretarios. Estos funcionarios se encargaban en deliberar sobre asuntos que le competían al soberano, a través de normas tales como: las Cedulas Reales y las Ordenanzas; (HAGGIN: 1972: 112) el fiscal se encargaba de la defensa de la jurisdicción real "la del patronato eclesiástico que los reyes ostentan por bula papal sobre la iglesia del Nuevo Mundo; de la Real Hacienda, y de los indios interviniendo además judicialmente en los pleitos, visitas y residencias que se juzgan en el Consejo". (GRAN ENCICLOPEDIA RIALP) Los Relatores encargados de sacar los resúmenes de los pleitos y las relaciones de las visitas y residencias. Los Secretarios:

Son secretarios de esta Cámara los mismos del Consejo se reúnen los lunes y miércoles. Sus atribuciones específicas son todos los asuntos de gracia y merced y la propuesta al Monarca de los altos cargos de gobierno, justicia y hacienda del Nuevo Mundo. Con anterioridad estas propuestas corrían a cargo del «pleno» del C. y sólo a Ovando durante su presidencia (1571-75). La creación de esta Cámara de Indias obedeció a la conveniencia de hacer personales las responsabilidades de las propuestas de las altas autoridades de Indias, de otro modo muy difusas. Las disposiciones emanadas de la Cámara se asientan en sus correspondientes libros cedularios -Islas, Nueva España, Perú. (GRAN ENCICLOPEDIA RIALP)

Las atribuciones del Consejo Superior de Indias consistían en funciones ejecutivas, legislativas y judiciales, todas ellas concentradas en una sola autoridad, su denominación de Real se dio porque asesoraba al monarca y actuaba con éste, supremo en tanto le estaban sujetos todos los Estados, reinos de Indias y, porque encima de él no había otro Tribunal.

La primera de estas funciones consistió en enviarle al Rey los nombramientos de los funcionarios de Indias que se encargaban de la creación y establecimiento de las Reales Audiencias en el territorio Americano; (MEDINA: 2002: 31) la segunda, en redactar, discutir y someter a la aprobación del Rey las leyes para las Colonias, al mismo tiempo que era órgano, consultor del Monarca decidiendo sobre las leyes finales para su promulgación; (MEDINA: 2002: 31) y por último, las funciones judiciales, intervenía como tribunal de apelación en los casos de contrabando y tenía a su cargo igualmente el trámite de juicio de residencia.

El Juicio de Residencia al cual eran sometidas todas las autoridades al término de sus respectivos gobiernos, era una labor fiscalizadora, que se hacía a los funcionarios que culminaban su labor; consistía en una rendición de cuentas que llevaba a cabo un funcionario delegado por el Consejo de Indias, denominado Juez de Residencia quien iniciaba una labor secreta investigativa, el cual se instruía a través de un informe donde se concretaba el comportamiento y el grado de cumplimiento de sus funciones; de igual forma, se adelantaba una pesquisa pública donde cualquier persona podía presentar quejas apoyadas en pruebas. El Juez de Residencia, se pronunciaba de todos los cargos y las sanciones solían ser desde la imposición de multas hasta la descalificación para ocupar cargos públicos; en todos los casos la última palabra la tenía el Rey. Así las cosas el Consejo, aprobaba o rechazaba el informe presentado de acuerdo a los antecedentes reunidos si el juicio era negativo podía implicar la terminación de la carrera del funcionario por el contrario si resultaba favorable lo habilitaba para ascender de grado. (AMORES: 2006: 282)

Otra institución que se dio en la colonia fueron los Virreinatos. El Virreinato de Nueva Granada, abarcó los territorios actuales de Colombia, Panamá, Venezuela y Ecuador, creado mediante Real Cédula el 27 de mayo de 1717 uniendo la Real Audiencia de Quito, la Capitanía General de Venezuela y la Real Audiencia de Santa Fe bajo la necesidad creciente de la Colonia de tener una autoridad que acercara la persona del Rey a los territorios de la Nueva Granada, ya que el Consejo Superior de Indias iba 
perdiendo prestigio. Por tal razón, se hacía indispensable una reorganización fundamental en el gobierno de ahí que, en 1717 se decretara la creación del Virreinato de Nueva Granada; con jurisdicción sobre todos los territorios que más tarde conformaron la Gran Colombia.

Como primer Virrey se conoce a Don Antonio de la Pedrosa y Guerrero, que tras luego de su corta permanencia en el gobierno plantó una nueva organización. Los virreyes se caracterizaban por ser los representantes del Rey en América; se les dio también el titulo de Capitán General, es decir Jefe Supremo de las fuerzas de mar y tierra, para que pudiesen organizar más cómodamente la defensa contra los enemigos internos y externos. De los Virreyes que tuvo la Nueva Granada se conocen los siguientes: Antonio de la Pedrosa y Guerrero (1717-1719), Jorge de Villalonga (17191723), (En 1723 el virreinato fue disuelto. Sus territorios pasaron a depender de la presidencia del Nuevo Reino hasta su restauración en 1739), Sebastián de Eslava (1739-1749), José Alonso Pizarro (1749-1753), José Solís y Folch de Cardona (1753-1761), Pedro Messía de la Cerda (1761-1772), Manuel de Guirior ( 1772-1776), Manuel Antonio Flórez y Angulo ( 1776-1782), Juan de Torrezar Díaz Pimienta (1782), Antonio Caballero y Góngora (1782-1789), Francisco Gil de Taboada y Lemos (1789), José de Ezpeleta (1789-1797), Pedro Mendinueta (17971803), Antonio Amar y Borbón (1803-1810). (QUINTERO, A: 1971: 113,168)

En un comienzo el nombramiento del Virrey se hacía de manera vitalicia, luego dicho mandato se limitó a tres años y más adelante se reguló hasta por cinco años. El Virrey ejercía como autoridad suprema en su jurisdicción indiana como Jefe Civil y Militar dentro de su unidad administrativa, también dependían de él la justicia, el tesoro y los aspectos laicos del gobierno eclesiástico; (LLANO: 2002: 42)

El período colonial en el Nuevo Reino se caracterizó por la alianza entre Estado, Iglesia y Sociedad. La investidura divina del Monarca, como defensor de Dios entre los hombres, y la imagen sacra del Papa, como representante de Dios en la tierra, sirviendo para estrechar las intenciones del esquema moral con el esquema jurídico". (BLANCO: 2005: 84)

Las ideas de Rousseau, Montesquieu no eran aceptadas por España ya que éstas se introducían a América con la finalidad de ilustrar, enseñar y hacer razonar a las personas acerca de cómo debía de ser la vida social y política. Se pregonaban los derechos a ser libres, a elegir sus propios gobernantes, a una igualdad social y jurídica, y así mismo se difundía la separación de la iglesia del Estado y se proponía que el gobierno fuera republicano.

El 29 de mayo de 1717 se instituyó el virreinato de Nueva Granada, suprimido en 1723 y restablecido definitivamente el año 1739. Su capital fue Santa Fe de Bogotá con jurisdicción sobre los territorios actuales correspondientes a Venezuela, Colombia, Ecuador y Panamá. Las consideraciones que manejó la corona para su creación giraron en torno a dos hechos esenciales. En primer lugar, la zona era la más importante del continente en cuanto a la producción aurífera. En segundo lugar, su situación estratégica entre los dos océanos y puerta de entrada a la América del Sur, le permitiría enfrentar mejor el contrabando y los ataques de piratas y filibusteros del Caribe.

En cuanto a la población del virreinato, señala Carlos Malamud:

A lo largo de la centuria, la población del virreinato fue en constante aumento, estimándose una tasa de crecimiento para el último cuarto del siglo del orden del 1,5 por 100 anual. Según el censo de 1778 , la población del virreinato, con exclusión de los territorios integrados en la Audiencia de Quito, ascendía a 742.759 habitantes. W.P.McGreevey estimó que la población de los territorios 
que forman la actual Colombia ascendía a 940.000 habitantes". Finalmente, la mayor concentración de población (62\%) se encontraba en los altiplanos andinos colombianos. (LA CREACIÓN DEL VIRREINATO DE NUEVA GRANADA)

La Real Audiencia fue el más alto tribunal de apelación en las Indias, se dividía en dos salas, una que atendía la jurisdicción civil y la otra con jurisdicción en lo criminal; por consiguiente, la creación de las Audiencias indianas tuvo como principal objetivo reafirmar la supremacía de la justicia del rey sobre la de los gobernadores. (LA CREACIÓN DEL VIRREINATO DE NUEVA GRANADA) Las Audiencias tenían una organización similar al Consejo de Indias, por autoridades colegiadas, letrados profesionales, cuatro Oidores y un Fiscal, presididos por el Virrey o gobernador de la zona, aumentando la cantidad de integrantes en los territorios más extensos. Cada año rotativamente un oidor debía realizar viajes de inspección y judiciales por las provincias que formaban parte de la jurisdicción de la Audiencia, este Tribunal Real asesoraba a la autoridad política del territorio asignado a su jurisdicción constituyéndose en un organismo consultivo de vital importancia para los Virreyes y Gobernadores. (LA CREACIÓN DEL VIRREINATO DE NUEVA GRANADA)

En Santafé de Bogotá de el Nuevo Reino de Granada resida otra nuestra Audiencia y Cancillería Real, con un Presidente, Gobernador y Capitán General: cinco Oidores, que también sean Alcaldes de el Crimen: un Fiscal: un Alguacil mayor: un Teniente de Gran Chanciller, y los demás Ministros y Oficiales necesarios, y tengan por distrito las Provincias del Nuevo Reino, y las de Santa Marta, Rio de San Juan, y Popayan, excepto los lugares, que de ella están señalados á la Real Audiencia de Quito, y de la Guayana, ó Dorado, tenga lo que no fuere de la Audiencia de la Española, y toda la Provincia de Cartagena, partiendo términos: por el Mediodía con la dicha Audiencia de Quito, y tierras no descubiertas: por el Poniente, y por el Septentrión con el Mar del Norte, y Provincias que pertenecen á la Real Audiencia de la española: y por el Poniente con la de Tierra firme. Y mandamos, que el Gobernador y Capitán General de las dichas provincias, y Presidente de la Real Audiencia de ella, tenga, use y ejerza por si solo la gobernación de todo el distrito de aquella Audiencia, así como le tienen nuestros Virreyes de la Nueva España, $y$ provea los repartimientos de Indios, y otros Oficios, que se hubieren de proveer, y despache todas las cosas y negocios, que fueren del gobierno, y los Oidores de la dicha Audiencia no se entrometan en lo que á esto tocare, y todos firmen lo que en justicia se proveyere, sentenciare $y$ despachare. (AUDIENCIA Y CANCILLERÍA REAL DE SANTAFÉ EN EL NUEVO REINO DE GRANADA)

En cada provincia se instituyó una Real Audiencia con el objetivo de controlar el ejercicio arbitrario y abuso del poder de los Virreyes, Gobernadores, Intendentes, Alcaldes y Corregidores, de tal forma que como Tribunal de Justicia conocía de los recursos de apelación de los Tribunales de rango menor (Corregimientos y Gobernadores). En los asuntos criminales la decisión de la Audiencia era definitiva, no había posibilidad de apelación, contrario a los asuntos civiles que si contaban con apelación ante el Consejo de Indias; (MEDINA: 2002: 31) por lo tanto, se vulneraba el derecho a tener una segunda instancia en las decisiones que tomaba este tribunal. Así mismo, uno de los juicios de mayor importancia, eran aquellos relacionados con los indios y españoles donde pretendía proteger al indígena considerándolo siempre en un estado de indefensión, asignándole con posterioridad un Procurador para la defensa y garantía de sus derechos.

Dicha Audiencia se integraba; por un Presidente, quien se encargaba de velar por el cumplimiento de las obligaciones de cada uno de los funcionarios que hacían parte de la Audiencia, 
igualmente designaba a los Oidores encargados de visitar las tierras, elegía a dos oidores para que cumplieran con la función visitar las cárceles de la Audiencia, de manera que los Oidores se caracterizaban de juzgar las causas civiles y criminales. (AMORES: 2006: 276)

Otro organismo representativo existente era el Cabildo cuya función principal era la administración en los municipios, estaba integrado por los Alcaldes Ordinarios y por los Regidores, se contaba con 12 regidores, ocho por compra del cargo y cuatro electos por el Rey a sugerencia del gobernado; (LLANO: 2002: 42) dentro de sus funciones los alcaldes ejercían como jueces en primera instancia en los juicios civiles y criminales que se suscitaban en el Cabildo. Los Regidores remplazaban eventualmente a los Alcaldes, se ocupaban de las cuestiones vinculadas con la policía de abastos, obras públicas y visitas de cárcel. (SANCHEZ, DE LA ERA, \& DIAZ: 1992: 213)

Sin embargo, la concentración de poder fue morigerada a finales del siglo XVIII, con la teoría de la división de los poderes de Montesquieu, el alcalde perdió la atribución judicial y el derecho a presidir las secciones del Cabildo y, conservó únicamente la función administrativa. (SANCHEZ, DE LA ERA, \& DIAZ: 1992: 213)

El anhelo de depositar la autoridad en "personas conocidas y determinadas", expresado por cabildo santafereño, se cumple en el marco de un proceso lento y conflictivo, pues ante la posibilidad de organizar un gobierno general y unitario, las provincias establecen el suyo propio y se confederan al margen de las constituciones de 1811 y 1812 , que por tal motivo rigieron tan solo para Cundinamarca. (SANCHEZ, DE LA ERA, \& DIAZ, 1992: 25)

\section{EL PODER JUDICIAL EN LA REPÚBLICA (1810-1821)}

En 1810, el cabildo de Santa Fe expide la declaración de independencia, la naciente república era predominantemente rural y campesina, su régimen de gobierno incipiente pues ante la imposibilidad de organizar un gobierno unitario y general, cada provincia establece el suyo propio... se confederan al margen de las constituciones de 1811 y 1812 . Ahora bien para hacer un análisis de cómo se organizó el poder judicial en la Nueva Granada es necesario observar, la estructuraba del poder judicial en las constituciones que se promulgaron en el periodo comprendido entre 1811 y 1821.

La Audiencia, " la mejor encarnación de la política española en América" definida la jurisdicción se sucede la organización e instalación de la Real Audiencia, tribunal integrado por juristas inauguran el ejercicio del derecho público y con él, el gobierno de leyes que prevalece y modela el alma nacional a lo largo de tres siglos, para renovar su vocación del derecho constitucional, preconizado ya en las clausulas memorables del Acta del Cabildo extraordinario del 20 de julio de 1810, bien conocida como la de la independencia Nacional. (HERNANDEZ: 2007: 354,506)

La concentración de poder que se ejercía en la Colonia obligó a que la naciente Nación pregonara garantías que sirvieran de limitante a los gobiernos razón por la cual, en las Constituciones Provinciales se observa la mención a la Declaración de Derechos del Hombre y del Ciudadano; como por ejemplo, en la Constitución de Cundinamarca, título 1, artículo 16, que establece que: " el gobierno garantizará a todos sus ciudadanos los sagrados derechos de la religión, propiedad y libertad individual"; (CONSTITUCIÓN DE CUNDINAMARCA: 1812) la Constitución de Tunja, en el Capítulo l, articulo 7 , expresa que " la ley debe proteger la libertad pública e individual contra la opresión de los que gobiernan", articulo 8 "ningún hombre puede ser acusado, preso, arrestado, arraigado ni confinado, sino en los casos y bajo las formulas prescritas por la ley". (CONSTITUCIÓN DE TUNJA: 1811) Los poderes legislativos, Ejecutivo y judicial fueron separados en diversas corporaciones o 
sujetos, con la finalidad de lograr los contrapesos necesarios que permitieran un equilibrio de fuerzas y razón por la cual, la división de la función pública entre diferentes ramas permite que el poder no descanse únicamente en las manos de una sola persona o entidad $y$, con ello los diversos órganos podrían controlarse recíprocamente.

Así las cosas, en el proceso de consolidar un poder judicial independiente de los demás poderes del Estado se siguió conservando rezagos de las instituciones de la Colonia:

Bolivar decreto - el 15 de septiembre de 1819 - la creación del Supremo Tribunal de Justicia de las Provincias Libres de la Nueva Granada, cuyas atribuciones serían las mismas que el Congreso de Angostura había asignado al Alto Tribunal de Venezuela por el reglamento mencionado. Para integrarlo nombro a los abogados neogranadinos Ignacio de Herrera (presidente), Antonio Viana, Nicolás Ballén de Guzmán (juez general de bienes de difuntos), Miguel Tovar (fiscal de lo civil y lo criminal) y José de Ignacio de Márquez (fiscal del ramo de Hacienda). Estos cinco magistrados y el procurador general de la Republica- encargado de "pedir y sostener la observancia de las leyes en el orden judicial"-, conformaron el tránsito de las altas funciones judiciales del Estado Indiano al nuevo estado republicano, dado que la Alta Corte de Justicia heredó de la Real Audiencia la potestad para fallar los recursos de segunda instancia interpuestos por los demás tribunales, asî como la de examinar a los abogados del Nuevo Reino y despacharles sus títulos. (MARTINEZ: 2008: 107).

Por consiguiente, la organización del poder judicial quedó integrado por los Alcaldes Ordinarios de los Cabildos, siguiendo con la organización que se traía de la colonia en las ciudades: igualmente, se continuó con los Alcaldes Pedáneos en los distritos de los Cabildos y, por otro lado se delegó a los gobernadores la facultad para conocer causas en segunda instancia de los asuntos que no sobrepasaran de mil pesos, con la finalidad de evitarles a los ciudadanos los costos en que concurrían a elevar sus peticiones ante la Corte Suprema. (MARTINEZ: 2008: 107)

\section{[...] Siguiendo una tradición indiana} que le había concebido esta facultad a los gobernadores de las provincias de Popayán y Panamá. También fueron autorizados para conocer causas del ramo de secuestros. Como algunos gobernadores entendieron que era posible crear tribunales provinciales, el Vicepresidente tuvo que recordarles que la Corte Suprema había recibido todo el legado de la Real Audiencia en la amplitud de causas que podrían conocer, al punto que el sello de la Republica que usaba daba cuenta de su atribución soberana. (MARTINEZ: 2008: 108).

De ahí que, la primera autoridad ejecutiva fue el Alcalde, con funciones administrativas pero no deslindadas del todo de las judiciales. Los alcaldes se les conoció con distintos calificativos tales como: ordinarios, pedáneos, de la hermandad, comisarios y letrados, preferentemente durante este confuso período comprendido entre los años de 1810 y 1815”. (HENAO: 2004: 25)

\subsection{Constitución de Cundinamarca}

La Constitución de Cundinamarca en su titulo VII, artículo 1, definió lo que se entiende por Poder Judicial: "autoridad de examinar las diferencias que se suscitan entre los ciudadanos, fijar sus derechos, juzgar sus demandas y querellas, y aplicar las penas establecidas por las leyes a los infractores de ellas. El uso ordinario de estos juicios es lo que propiamente se dice poder judicial", (CONSTITUCIÓN DE CUNDINAMARCA: 1812: 342) de tal forma que la organización del poder judicial se estructura de la siguiente manera: 1 . un Tribunal de la Provincia Preferente a todos los demás es el Senado, 2. Tribunales de Apelación, 3. los Jueces de primera instancia en las municipalidades. 
El primero de ellos, el Senado se conformaba de cinco miembros electos de la representación Nacional, a saber; el Vicepresidente de ella y cuatro Senadores; el vicepresidente de la Representación Nacional ejercía por un período de tres años y los cuatros senadores se renovaban por mitades cada dos años, saliendo los dos más antiguos, los miembros que ingresaban para ocupar el cargo de los salientes eran nombrados expresamente para este efecto por los electores a finalizar cada año. A este Senado le corresponde el juicio de Residencia de los miembros de la Representación Nacional, igualmente el Senado tomaba a consideración cualquier queja o documento que se le dé por cualquier poder, ciudadano o funcionario público habiendo algún miembro de los tres poderes (Ejecutivo, Legislativo y Judicial), que hubiere usurpado facultades de otro $\mathrm{u}$ otros quebrantando la Constitución. (CONSTITUCIÓN DE CUNDINAMARCA: 1812: 342)

\section{El juicio de residencia}

Esta institución controlo los actos de los empleados públicos de los tres poderes. La Constitución de Cundinamarca, de 1811, ordenó, en el articulo 34, sección II, titulo II, que todo empleado de los tres poderes al ser responsable a los pueblos por su conducta oficial, debía sufrir juicio de residencia al terminar sus funciones.

[...] el juicio de residencia era adelantado por un grupo de nueve senadores a quienes se le señalaba para cada caso, con el fin de evitar que los jueces fueran cercanos a los investigados, para algunas situaciones en particular se vincularon como investigadores a algunos representantes quienes asumían el papel de senadores para el caso especifico, mientras los senadores compañeros de los investigados debían ausentarse de la sala durante las secciones correspondientes. (BLANCO \& CÁRDENAS: 2010: 105,106)

En el desarrollo del juicio de residencia se contemplaba que cada año se elaborara un listado de los funcionarios de la representación nacional que habían terminado funciones en el año anterior, esta lista circulaba por la provincia para que los ciudadanos presentaran las reclamaciones pertinentes. Así mismo, correspondía al Senado pedir la prisión de la personas que resultaran comprometidas con las investigaciones adelantadas, el Juicio de Residencia se adelantaba ya fuera para someter a los empleados públicos una vez terminaban el ejercicio de sus funciones, este mismo procedimiento se adelantaba para aquellos funcionarios que querían cambiar de trabajo. (BLANCO \& CÁRDENAS: 2010: 105,106)

El segundo organismo del Poder Judicial, era el Tribunal de Apelación y Jueces de Primera Instancia, muy importante, toda vez que entre sus funciones se encontraba la guarda y defensa de los Derechos del Hombre y del Ciudadano donde se consagró el principio de legalidad de la siguiente manera: "Ninguna persona de cualquier clase, estado y condición que sea podrá ser aprehendida por ninguna autoridad ni fuerza militar, sino para presentarla al tribunal competente; y nadie puede arrestar o poner en presión sin mandato formal de Juez competente, dado por escrito". (CONSTITUCIÓN DE CUNDINAMARCA: 1812, Titulo VII, Art. 37) Por otro lado, se contemplaba el arresto para causas civiles, teniendo por lo menos prueba verdaderamente semiplena; (CONSTITUCIÓN DE CUNDINAMARCA, 1812, Titulo VII, Art. 38) para ser miembro del poder judicial se requería: 1. Tener como mínimo 25 años de edad, 2. Cualidades de vecindad, crédito y buena opinión, 3. Ser abogados. Los fiscales debían cumplir con los mismos requisitos. (CONSTITUCIÓN DE CUNDINAMARCA: 1812, Titulo VII, Art. 52,53)

\subsection{Constitución de la República de Tunja}

El poder judicial en la Constitución de Tunja, es muy similar a lo contemplado en la Constitución de Cundinamarca pero con grandes diferencias en lo concerniente a los miembros del poder judicial $y$, adicional a esto se presenta rezagos de la organización administrativa y judicial 
de los tiempos de la colonia, como se verá a continuación; el poder judicial se conformaba de los siguientes miembros: Gobernador, Alcaldes Pedáneos, Alcaldes Ordinarios, Tribunal de Apelaciones, Sala de Últimos Recursos y Jurados de las Causas Civiles.

En primer lugar estaba al gobernador, quien conocía en primera instancia de los asuntos políticos, administrativos y económicos y era aconsejado por el teniente gobernador, figura propia del de la estructura política del Estado colonial. (LLANO: 2002: 42) Los Alcaldes Pedáneos, esta figura de origen español, es el nombre que se le otorgó en España al órgano ejecutivo unipersonal que se sitúa al frente del gobierno local de una entidad de ámbito territorial Inferior al municipio, siendo estas entidades submunicipales. El Alcalde Pedáneo vendría a ser el Alcalde de un Núcleo de población, generalmente rural y de pequeño tamaño (una aldea), situado dentro un término municipal regido por otra localidad mayor; (CONSULTOR DE LOS AYUNTAMIENTOS Y DE LOS JUZGADOS MUNICIPALES) esta figura es muy similar a los Alcaldes contemporáneos, a diferencia de que aquellos tenían entre sus funciones: conocer de las causas civiles en una cuantía hasta de doscientos pesos y, en lo criminal sus funciones iban en la formación del sumario, arresto y confesión, dando cuenta en este estado a la justicia ordinaria.

Los Alcaldes Ordinarios, "en cada uno de los departamentos se elegirán dos o tres o más alcaldes ordinarios, en cuyo juzgado se decidirán en primera instancia todos los asuntos contenciosos que ocurrieren en el distrito, a prevención con los pedáneos, en los casos a que estos pertenece". (CONSTITUCIÓN DE TUNJA: 1811: 450)

El tribunal de apelaciones, este organismo resulta bastante particular en lo que tiene que ver en su organización y funcionamiento, toda vez que es similar a la Real Audiencia lo que cambia es su nombre como se puede evidenciar en el capítulo IV (el tribunal de apelaciones ), Art 1,2,3,4,5,6 y 7 de la Constitución de Tunja.
1. Las demás apelaciones de las sentencias que pronunciaren los alcaldes ordinarios se llevaran al alto Tribunal de Justicia que residirá en la capital de la provincia, en los términos que antes se hacía para la Real Audiencia del Reino.

2. Este tribunal se compondrá de tres ministros letrados, un fiscal que despache en los asuntos civiles y criminales, un relator y un secretario [...].(CONSTITUCIÓN DE TUNJA: 1811: 451)

De ahí que la Sala de últimos recurso, en los casos en que el Tribunal de Justicia apele ante la sala de últimos recursos, procedía a enviar una lista de ocho sujetos de prioridad y buenas luces que se llamaban conjueces; esta lista se presentaba a las partes y cada una de ellas podía excluir dos de ellas para que los cuatro restantes revisen el proceso y pronunciaran su juicio ${ }^{1}$.

Finalmente los Jurados, se componían de 12 sujetos los cuales eran llamados para el conocimiento de la causa, previo acuerdo por las partes donde se consideraba que éstas acudían al jurado porque lo consideraban más seguro para no aventurar la justicia; la elección del jurado debía ser de propietarios que habitaran dentro del distrito, que ostentaran bienes muebles $e$ inmuebles en una cantidad que no fuera inferior de quinientos pesos; también, debían tener las cualidades para ser Juez, la presentación de los procesos ante jurado sólo procedía en los asuntos de mayor cuantía.

\subsection{Constitución del Estado de Antioquia}

En el titulo 1, Sección segunda "De los derechos del hombre en sociedad", se consagran cuatro derechos fundamentales, la libertad y la igualdad legal, y, la seguridad y la propiedad. Consolidándose cambios importantes en cuanto a las atribuciones del pueblo para escoger sus gobernantes, (RESTREPO: 481) cambio de régimen absolutista a uno democrático con un desconocimiento de las leyes de España; (CONSTITUCIÓN DEL ESTADO DE ANTIOQUÍA: 1812) con el fin de darle al pueblo una Constitución que garantizara la seguridad y felicidad de los hombres. 
En el Título V, Sección primera, artículo 1, se define el Poder Judicial de la siguiente manera:

El Poder Judicial es la facultad de aplicar las leyes a los casos particulares, ya sea decidiendo las querellas y demandas que ocurran entre partes, dando a cada ciudadano lo que le pertenece. Ya imponiendo a los delincuentes e infractores las penas que han establecido las mismas leyes, o administrando justicia civil y criminal en todo lo contencioso. (CONSTITUCIÓN DEL ESTADO DE ANTIOQUÍA: 1812:. 4)

De tal forma, se contempla el vínculo que debe existir en las relaciones jurídicas del Estado con sus asociaciones, esta relación jurídica tiene un contenido de derechos y deberes reciproco contextualizando un Poder Judicial como medida de derecho; es decir se regulan los derechos y el modo de usuarios estableciendo sus limites, esto es lo que se denomina legalidad de la ley.

[...] la ley no ha de establecer penas crueles, sino proporcionadas a la naturaleza de los delitos: ellas deben ser escrita y evidentemente necesarias y útiles a la sociedad.

[...] ninguno debe ser juzgado, ni castigado sino después de habérsele oído y convencido legalmente, $y$ en virtud de una ley promulgada antes de cometerse el delio. Las leyes que castigan acciones que precedieron a su existencia, y que solo por ellas han sido declaradas criminales son injustas, tiránicas $e$ incompatibles con la libertad. Así, ninguna ley civil ni criminal puede tener efecto retroactivo. (CONSTITUCIÓN DEL ESTADO DE ANTIOQUÍA: 1812: 4)

El principio de legalidad de la ley y de igualdad ante la misma genera prevenciones acerca del poder judicial, con postulados como los siguientes: todos los hombres son iguales delante de la ley, no se pondrá delito distinto al noble que al plebeyo, la recta administración de justicia dota a los tribunales de facultades para coartar la libertad de los ciudadanos de tres formas; la primera con prisión, el segundo con arresto domiciliario y el ultimo por arraigo, mandando se mantenga la persona en el poblado de su residencia; se contempla la prisión y el arresto para las causas tanto civiles como criminales.

Uno de los principales a objetos será el que la justicia se administre tan pronta $y$ gratuitamente cuando fuere posible. Para conseguirlo estrechara los términos y plazos judiciales, reformara los abusos de llevar costas excesivas, reprimirá las prisiones y pesquisas arbitrarias castigándolas con el mayor rigor: en una palabra la legislatura aplicara todos sus ciudadanos a la reforma de los juicios, ese ramo tan defectuoso de la legislación nacional, para que los derechos de los ciudadanos no se vulneren: para que sea escuchada la voz de la razón, y hasta el ultimo individuo de la sociedad goce de la libertad civil en toda su plenitud. (CONSTITUCIÓN DEL ESTADO DE ANTIOQUÍA: 1812: 4)

En efecto, desde el punto de vista de lo conceptuado en la Constitución es claro que no se debe confundir lo que es justo con la norma jurídica entendiendo esta última como una ordenación de los comportamientos humanos hacia los fines de la sociedad, o como delimitación de esferas de libertad. (HERVADA: 2000: 117)

El Poder Judicial se estructuraba de la siguiente forma: como Órgano principal, el "Supremo Tribunal de Justicia" conformado por cinco ministros y un fiscal que llevaba al mismo tiempo las causas civiles y criminales, en el gobierno y hacienda. En la elección del Tribunal se nombraba a 2 ministros por un período de un año, dos mas por dos años y los restantes por tres años eligiéndose el Presidente del Tribunal y el fiscal; la presidencia se turnaba anualmente, eligiendo el tribunal por suerte, al ministro que ha de suceder en ella. En los eventos en que algún ministro se encuentre impedido lo remplazaba el fiscal y, si éste se encontraba 
impedido se nombraba conjueces que juzgaban las causas de los ministros impedidos.

Así las cosas, el Tribunal conocía de las segundas y terceras instancias, en Apelación o Súplica de todos los asuntos contenciosos, tanto civiles como criminales, que se sucintaban en el distrito de la provincia; el Supremo Tribunal de Justicia conoce en única instancia de las causas civiles en que sean reos los miembros de los tres poderes. De la Corte de Justicia:

Articulo 1. Los recursos extraordinarios que por nuestras leyes se hacían al soberano, a los consejeros supremos establecidos en España, se introducirá en la Cámara de Representantes, quien inmediatamente $y$ sin dictar un solo decreto, que mire a su determinación, mandara, formar un tribunal o alta Corte de justicia, pasando enseguida aviso de resolución a la Cámara de Senadores. 2. Cada una de las cámaras sacara por suerte dos individuos de los de su sala, quienes unidos al presidente del estado formaran el tribunal: mas el presidente solo tendrá voto en caso de discordia.

3. Inmediatamente después de interpuesto alguno de dichos recursos, cualquiera de los litigantes manifestara sencillamente a cada una de las cámaras, aquel o aquellos individuos que en ella se hallen impedidos de conocer en su recurso, y las cámaras si considerasen justas las causales expuestas, los excluirá del sorteo. (HERVADA: 2000: 117)

Acto seguido se encuentra los jueces de primera instancias, que conocerán de todo lo contencioso en los ramos de policía y gobierno, de hacienda publica; del mismo modo, será el que conozca de los negocios civiles y criminales, en que tenga fuero los empleados de rentas.

Los tenientes, alcaldes ordinarios, jueces pobladores, capitanes de guerra, alcaldes de la hermandad y jueces pedáneos, conocerán privativamente de todas las primeras instancias en los asuntos contenciosos entre partes, tanto civiles como criminales. (HERVADA: 2000: 48)

Por tanto, ningún Juez en calidad de tal llevara costas procesales, ni admitirá demanda por escrito, sin que se haya precedido sobre ella un juicio verbal, dicho procedimiento inicia con el nombramiento de tres vecinos haciéndoselo saber al actor y reo, se borrara uno de la lista, para que el tercero sea quien los oiga verbalmente, ejerciendo las funciones de pacificador; una vez las partes hayan aclarado el asunto ante el pacificador, se remitirá una boleta por el juez que le nombró, expresando en ella el resultado de su encargo, de tal forma que será nulo todo proceso que no se conduzca con estas diligencias. (HERVADA: 2000: 48)

\subsection{Constitución del Estado de Cartagena de Indias}

El Titulo VII, Articulo 1, define en que consiste el Poder Judicial, "autoridad de oír, juzgar y fenecer las diferencias, demandas y querellas que se susciten entre los ciudadanos, pronunciando la determinación de la ley y en la de aplicar la pena que ella impone al delincuente". (POMBO \& GUERRA: 1991)

El ejercicio de este poder, como parte de la convención general de poderes del Estado, corresponde sólo a los Tribunales Superiores; los Jueces de Primera Instancia, los inferiores y las municipalidades no tienen parte en ella, aunque la tenga en el ejercicio del Poder Judicial.

El orden y graduación de los Tribunales del Estado de Cartagena es el siguiente: el Senado conservador, el Supremo Tribunal de apelaciones, los Jueces de Primera Instancia y, Pedáneos con los Consejos por pequeños que estos sean. (POMBO \& GUERRA: 1991)

El Senado se componía de cinco miembros, nombrados por el Colegio Electoral, un Presidente, que será Vicepresidente nato de la convención general de poderes, quien permanecerá en 
ejercicio por tres años y cuatro Senadores quien ejercían el cargo por mitades cada uno, saliendo los dos mas antiguos, le corresponde al Senado el juicio de residencia de los individuos de la convención de poderes que salgan cada año. En consecuencia, a principio de cada año circula el Senado por todos los departamentos del Estado la lista de los funcionarios que han concluido el año anterior $y$, convoca a todo aquel que se sienta agraviado para que dentro de los dos meses concurran a producir contra ellos las quejas o demandas respecto al ejercicio de sus funciones; cerrado el juicio no podían ser ya acusados o juzgados en razón de los empleos que obtuvieron. (POMBO \& GUERRA: 1991)

El Senado es Juez privativo de los miembros de la convención de poderes durante el ejercicio de sus funciones; la provincia del Senado se extiende solamente a remover del oficio al funcionario, y a declarar inhábil para obtener el empleo en el Estado, sea condenado o absuelto queda sujeto a ser juzgado conforme a las leyes por quien corresponda.

El Tribunal Supremo de Justicia será segunda instancia del corregidor intendente y de los Alcaldes y Juzgados Ordinarios de Primera Instancia de todo el Estado, en todos los asuntos contenciosos de Gobierno, Hacienda, Justicia civil y criminal. El Tribunal estaba integrado de 6 ministros y se dividirá en 2 salas a discreción del presidente de la misma para el conocimiento de las segundas instancias. Dos de los ministros hacían las veces de fiscales; pero serán jueces en la causa en la sala que no intervengan como tales, de tal forma que sin presencia de los tres ministros no podrá haber pleito alguno; los dos abogados más antiguos serán conjueces natos en todos los casos en que deba aumentarse el numero de ministros o para suplir el impedimento temporal de alguno de ellos. (POMBO \& GUERRA: 1991)

Los ministros del Tribunal Supremo desempeñaran su cargo hasta tanto su buen desempeño lo permitiera, eran nombrados por el colegio electoral, en los casos de muerte, enfermedad o demás que le imposibilite desempeñar su cargo, nombrando el Senado por terna del Poder Legislativo quien le sustituya hasta la reunión del colegio.

19. para ser ministro, además de la edad de veinte y dos años y cualidades de vecindad, crédito y buena opción, deberán ser abogados recibidos o incorporados en los tribunales del Estado.

20. no pueden ser miembros al mismo tiempo miembros del tribunal ascendientes o descendientes, hermanos, tíos y sobrinos carnales, primos hermanos, ni los parientes dentro del segundo grado de afinidad. (POMBO \& GUERRA: 1991)

Los Conjueces de primera instancia conocen de la administración de justicia civil y criminal entre partes, ejercida por los Alcaldes Ordinarios de los pueblos en primera instancia; no había apelación para los Cabildos en los lugares fuera de la capital donde haya Jueces Ordinarios se apelara entre ellos mismos.

No habrá en adelante casos de corte, y toda causa civil o criminal deberá verse en primera instancia por los jueces ordinarios de sus respectivos territorios, con apelación al tribunal de ellas.

Del corregidor intendente y de los alcaldes $y$ juzgados ordinarios de primera instancia de todo Estado, se apelara para el Supremo Tribunal de Justicia residente en la capital, en todos los asuntos contenciosos de Gobierno, Hacienda, Justicia Civil, Constara por ahora de este Tribunal del que actualmente existe con esta denominación, y dos ministros que se le agregaran, de manera que venga a componerse de seis. (POMBO \& GUERRA: 1991)

Los Alcaldes Ordinarios conocerán en primera instancia de las causas de comercio, con dos diputados, cuatro nombrados por cada una de las respectivas municipalidades y la apelación ira al Supremo Tribunal de Justicia; se suprime en esta Constitución las denominaciones particulares de Alférez Real, Ejecutor y Alguacil Mayor, las funciones de éstos la desempeñaran 
los regidores, los Alcaldes que concluyen quedan para el año siguiente de diputados del común y el uso de ellos hará de su Personero. De esta manera, se forma una pequeña municipalidad que cuide de los intereses comunes del pueblo y de los objetos del bien público con la debida, dependencia de los Cabildos de sus cabeceras. De ahí que la Constitución de Cartagena contemple en su Titulo I, "de los derechos naturales y sociales del hombre y sus deberes", que entrando en sociedad el hombre deja de ser un pequeño todo y consciente en hacerse parte de un gran todo político; los poderes de la administración publica formaran tres departamentosseparadosy cadauno de ellosserá confiado a un cuerpo particular de magistratura, a saber: el poder ejecutivo, legislativo y judicial, entre tanto el Estado de Cartagena se gobernara bajo la forma de republica representativa.

\subsection{Constitución del Estado de Mariquita}

Esta Constitución contemplaba un titulo denominado "de los Derechos de los habitantes de la Republica de Mariquita", en el cual las obligaciones del Estado con sus asociados y los deberes de estos con la sociedad, guardaba una constante en una aparente transcripción de los Derechos del Hombre y del Ciudadano promulgados desde la Revolución Francesa.

En otro orden de ideas, el Estado de Mariquita define el Poder Judicial como

la facultad de aplicar las leyes a los casos particulares, ya sea decidiendo las querella las demandas que ocurran entre las partes, dando acadaciudadanolo quele pertenece, ya imponiendo a los delincuentes e infractores las penas que han establecido las mismas leyes o administrando justicia civil criminal en todo lo contencioso. (POMBO \& GUERRA: 1991: 312).

Se puede observar de la definición que se da del poder judicial un contenido ius naturalista donde el ser humano tiene derechos anteriores al Estado y, por consiguiente lo justo es darle a cada uno lo que lo corresponde. Por lo tanto, solamente son del poder judicial estas materias y por ningún motivo podía entrometerse en lo referente a los poderes legislativos y ejecutivo, aunque sea en un asunto contencioso.

El Poder Judicial reside en la Sala de Apelaciones, Alta Corte de Suplicas de las municipalidades y Jueces Subalternos, el primero de ellos se integra de tres ministros y un fiscal que lleva la voz en lo civil, en lo criminal y en el gobierno, la presidencia se turnaba anualmente, eligiendo la sala por suerte al ministro que ha de suceder en ella. Conoce de todos los asuntos contenciosos tanto civiles como criminales que se susciten en el distrito de este Estado. (POMBO \& GUERRA: 1991: 314)

Siempre que se elegía un conjuez, el tribunal escogía tres individuos y se lo hacia saber al actor y al reo para que estos rechazaran uno de estos el que resultaba electo fungía como conjuez, para ser miembro de la Sala de Apelaciones, se necesitaba ser abogado y tener una edad mínima de veinte cuatro años y ser natural de América, el tiempo de duración de los miembros del tribunal dependía de su desempeño.

La Alta Corte de Súplicas quien conocía en última instancia de las causas que conocía la Sala de Apelaciones, se conformaba de un ministro de la Sala de Apelaciones sacado a la suerte en calidad de presidente y cuatro sujetos de rectitud y de las mejores luces posibles, con el nombre de Conjueces, los Jueces se ceñían a la estricta observancia de las leyes, y en caso de no haber ley aplicable al hecho ocurrido, lo sometían a la legislatura de la provincia, para que estableciera una ley que en lo sucesivo se aplicara en los casos iguales.

Las Municipalidades y Conjueces subalternos se conformaban de cinco personas dos de ellas alcaldes ordinarios y los tres restantes como regidores, en cada departamento existían un Presidente del Cabildo, bajo el titulo de "Juez Mayor de Paz", que se encargaba de conciliar amigablemente entre todos los ciudadanos de su respectivo departamento las diligencias en 
cualquier asunto civil. Si una vez terminada la conciliación y esta no se lograra de manera satisfactoria se elaboraba acta que deba constancia de no conciliación para que asi se pudiera llevar la demanda por escrito a los Tribunales de Primera Instancia, por lo tanto sin el pace del Juez Mayor de Paz no se podía por parte del Juez o Alcalde admitir demanda ni escrito sobre esta clase de materias. Para ser Juez se requería la edad de veinte y cinco años, haber sido vecino dentro del departamento donde era elegido por tres años, un juicio y una propiedad acreditada. (POMBO \& GUERRA: 1991: 322)

\subsection{Constitución de la Republica de Colombia 1821.}

La Gran Colombia, el 17 de diciembre de 1819 fue dictada la ley fundamental. La República de Colombia queda dividida entres grandes departamentos, así; Venezuela, (Capital Caracas, Cundinamarca el antiguo Nuevo Reino de Granada, Capital de Bogotá y Quito el actual Ecuador Capital Quito). El gobierno seria ejercido por un presidente y cada departamento, a su vez contaría con un Vicepresidente.

La batalla de Boyacá que puso fin al colonialismo español en el territorio de la Nueva Granada, abrió el espacio para que con la Constitución de 1821 se organizara la Colombia, Venezuela, Ecuador, Perú Bolivia y Panamá. Dicha unión, inspirada primordialmente por el Libertador Simón Bolívar, constituyo una estrategia militar y política, inicialmente en defensa de las libertades conseguidas y luego, en busca del consentimiento de su autonomía, pero pensando también las posibilidades de desarrollo, especialmente económico, a que podría llegar. (BLANCO: 2007: 72).

Una nueva forma de organización de las nuevas naciones libres se dio en el Congreso de Angostura, instalado el 15 de febrero de 1819. uno de los aspectos mas importantes de este Congreso fue la reunión de Venezuela y Nueva Granada, bajo el nombre de la Republica de
Colombia, el nombramiento del General Bolívar como Presidente de Colombia y la convocatoria a un Congreso General en Villa del Rosario de Cúcuta, el $1^{\circ}$ de enero de 1821, para consolidar la unión pactada. (BLANCO: 2007: 74)

La Constitución de 1821 contemplando en su Titulo VI, que la administración de justicia esta en cabeza de una Alta Corte de justicia compuesta por cinco magistrados con titulo de abogado y mayores de 30 años, Tribunales Superiores Departamentales establecidos por el Congreso donde se juzgara su necesidad, y los juzgados inferiores heredados del antiguo régimen. (POMBO \& GUERRA: 1991: 94)

Los funcionaros de la Alta Corte conocía de los asuntos contenciosos de embajadores, ministros, cónsules o agentes diplomáticos, de las controversias que resultaran de los tratados, negociaciones que hiciera el poder ejecutivo, de la competencia promovida en los Tribunales Superiores.

Art. 147. Para la más pronta y fácil administración de justicia, el congreso establecerá en toda la republica las cortes superiores que juzgue necesarias, o que las circunstancias permitan crear desde ahora, asignándoles el territorio su respectiva jurisdicción y los lugares de su residencia.

Art. 148. Los ministros de las cortes superiores serán nombrados por el poder ejecutivo, a propuesta en terna de la alta Corte de Justicia. Su duración será la expresada en el artículo 145.

Art. 149. Los juzgados inferiores subsistirán por ahora en los términos que se prescriban por la ley particular, hasta tanto que el congreso varié la administración de justicia. (POMBO \& GUERRA: 1991:. 94)

La intervención del poder ejecutivo en la administración de justicia no se limitó a la provisión de los magistrados de las Cortes, pues la Constitución facultó al ejecutivo para cuidar "de que la justicia se administre pronta 
y cumplidamente por los Tribunales y Juzgados de la República, y de que sus sentencias se cumplan y ejecuten". Se trataba entonces de una labor permanente del jefe del poder ejecutivo, para mantener la separación de los poderes públicos. (MARTINEZ: 2008: 111)

El titulo VI, del Poder Judicial, Sección Primera, de las atribuciones de la Alta Corte de Justicia elección y duración de sus miembros, en su artículo 140, que se integraba de cinco miembros denominados ministros, estos eran propuestos por el Presidente de la Republica a la Cámara de Representantes en numero triple, la Cámara redujo el número a dos miembros y lo presenta al Senado para que este nombre a los que compondrían. (BLANCO \& CÁRDENAS: 2010: 105,106)

Los ministros de la Corte elegían anualmente, a pluralidad de votos un presidente, entre los tres Jueces, las funciones del Presidente de la Corte conocía de los negocios de Embajadores, Ministros, Cónsules o Agentes Diplomáticos, conocía de las causas criminales y de la separación y suspensión de los Ministros de las Cortes Superiores conocer de las causas criminales y civiles que suscitaban de los secretarios del despacho, conocían en tercera instancia de las causas que contemplaban pena de muerte. (BLANCO \& CÁRDENAS: 2010-2: 81)

El Juez más Antiguo conocía de los asuntos que se suscitaban contra el Presidente de la Corte, en los asuntos que eran de su competencia. El juez menos antiguo conocía en primera instancia de los asuntos contra los empleados al servicio de la Corte. (BLANCO \& CÁRDENAS: 2010-2: 85)

Por consiguiente la Corte tenía a su cargo los negocios contenciosos de las causas civiles de cuantía de mil pesos, cuando hubiera lugar a tercera instancia, debatían sobre la inteligencia de alguna ley y consultaban sobre ella al presidente, "examinar las listas de las causas civiles y criminales que debían remitirle las Cortes Superiores, para promover la pronta administración de justicia, pasar copia de ellas al gobierno, y disponer su publicación por medio de la imprenta". (BLANCO \& CÁRDENAS: 2010-2: 82)
Ahora bien los Tribunales Superiores de Justicia se conformaban de nueve magistrados de los cuales sietes de los mismos eran Jueces y dos Fiscales entre ellos se elegía un Presidente del Tribunal Superior según su antigüedad aran nombrados los demás Jueces, el mas antiguo remplazaba al presidente en los momentos en que este no podía residir.

Por lo tanto le correspondía a los Tribunales Superiores conocer de la segunda y tercera instancia de las causas civiles y criminales de los Jueces y Tribunales inferiores de su distrito, conocer de la suspensión y separación de los Intendentes, Gobernadores y Alcaldes Ordinarios y Regidores, conocer de primera y segunda instancia de las causas de suspensión y separación de los delitos en que incurran por razón de su oficio, los Relatores, Secretarios y demás subalternos al servicio del Tribunal." Recibir de los Tribunales y Juzgados Subalternos avisos puntuales de las causas que se formaran por delitos, las listas de las causas civiles y criminales pendientes, para promover su pronta administración, y disponer de su publicación". (BLANCO \& CÁRDENAS: 2010-2: 82)

Asímismo los Tribunales Superiores se componían de dos salas, cada una con tres Jueces así una sala conocía en primera instancia un asunto la otra lo conocía en segunda instancia dejando la tercera instancia para la Corte Suprema quien conocía en tercera instancia, de tal forma que cuando el asunto provenía de los Tribunales Inferiores, el Tribunal Superior conocía en tercera instancia.

\section{CONCLUSIONES}

Las constituciones provinciales del periodo comprendido entre 1810-1821, caen en el insostenible juicio de reproche de la comunidad al descuidar los capítulos judiciales, pues infringen la regla de su primacía jurídica de su carácter de normas independientes cuando en la parte institucional no se estructura adecuadamente un poder judicial independiente con autoridad y poder para imponer la ley de forma tal que los 
principios que se pregonan el la carta fundamental se dan por decisiones coyunturales legislativas a conveniencia del poder administrador.

Las autoridades en la Republica no pudieron desarraigarse de las instituciones jurídicas españolas de forma absoluta ejemplo de ello se encuentra en el Tribunal de Apelaciones, organismo análogo a la Real Audiencia que funciono en la colonia como se puede observar en el capítulo IV, el Tribunal de Apelaciones de la Constitución de Tunja que contemplo que las sentencias que dictaban los Alcaldes Ordinarios se llevaban al Alto Tribunal de Justicia que residirá en la capital de la provincia, en los términos que antes se hacía para la Real Audiencia del Reino.

Ahora bien una autoridad ejecutiva que guardó la concentración del poder en el municipio donde el Alcalde tenia funciones administrativas y Judiciales, recibiendo distintos calificativos: Ordinarios, Pedáneos, entre otros desfigurándose lo que se pretendía bajo la concepción de los postulados angloamericanos y franceses donde la división de los poderes pilar fundamental para el buen funcionamiento del Estado lo que se evidencia en las constituciones es que el concepto de la división de poderes se manejaba a conveniencia de la agenta política de los dirigentes del momento, si bien se pretendía limitar el poder, este no se garantizó con el solo hecho de dejarlo estipulado en el papel, los postulados de la revolución francesa donde se debía garantizar la libertad del ciudadano en un Estado de Derecho mas bien se reformuló hacia la protección y libertad de interés particulares de clase naciente en la Republica.

Pues bien, el sistema de contrapesos es un sistema que se basa separación de poderes, descentralización, la libertad como principio esencial contra el despotismo, garantizada por la tridivisión del poder. Por consiguiente, no hay libertad cuando se confunden los tres poderes o no están bien delimitadas las competencias dentro del Estado. Por lo tanto, si lo mencionado anteriormente sucede, aparecen leyes abusivas y tiránicas, donde se puede disponer de la vida y derechos de los ciudadanos.

El ideal de que un poder judicial independiente evita la arbitrariedad siendo un freno para el poder ejecutivo si la separación de los poderes públicos están sometidos a la ley de manera igualitaria. Entonces, en este marco, el Poder Judicial deberá ser independiente para poder someter al resto de los poderes, muy especialmente al ejecutivo, cuando este contravenga de alguna manera el ordenamiento jurídico, presupuesto que no se da con eficiencia y claridad en las Constituciones Provinciales más aun cuando se conservan instituciones monárquicas de España donde el poder absoluto o por lo menos la concentración de poder es el eje fundamental en la administración del Estado.

De igual forma se trae como una institución fiscalizadora de los deberes de los funcionarios de gobierno el juicio de residencia se contempla en las constituciones provinciales para controlar el abuso del poder y por que no decirlo era una institución conveniente para inhabilitar a un funcionario para ejercer cargos públicos a conveniencia del poder político dominante así las cosas se puede observar que este juicio se contemplo en la Constitución de Antioquia 1812 articulo 34, constitución de Cundinamarca articulo39, constitución de Tunja 1811 artículos 9,10 y 11 y Constitución de Antioquia 1815 , lo distinto en cada una de las constituciones fue el termino para presentar las quejas ante los funcionarios. La conformación del Poder Judicial Autónomo e Independiente no obtuvo una colaboración funcional entre todos los órganos del estado para que así se respetara un mínimo de autonomía para el ejercicio de las funciones que se les reconocían por mandato Constitucional. Por lo tanto, el principio de separación es un presupuesto necesario pero insuficiente para garantizar la independencia de los poderes. La independencia requiere que el Poder Judicial ejerza el gobierno sobre sí mismo y por consiguiente, la separación de las ramas del poder público es inherente al régimen democrático y constituye uno de sus elementos procedimentales de legitimación del poder estatal. 


\section{FUENTES}

\section{Secundarias}

CONSTITUCIÓN DEL ESTADO DE ANTIOQUÍA. (1812) sancionada por los representantes de toda la provincia y aceptada por el pueblo el 3 de mayo del año de 1812. En. http:// www.cervantesvirtual.com/obra/constituciondel-estado-de-antioquia-sancionada-por-losrepresentantes-de-toda-la-provincia-y-aceptadapor-el-pueblo-el-3-de-mayo-del-ano-de-1812--0/

CONSTITUCIÓN DEL ESTADO DE CARTAGENA DE INDIAS. (1812).

CONSTITUCIÓN DEL ESTADO DE COLOMBIA. (1821).

CONSTITUCIÓN DE CUNDINAMARCA. (1812). Santa fe de Bogotá, Colombia: Imprenta Patriótica, de D. Nicolás Calvo Quijano.

CONSTITUCIÓN DEL ESTADO DE MARIQUITA. (1816)

CONSTITUCIÓN DE TUNJA. (1811). Santa fe de Bogotá, Colombia: Imprenta Patriótica, de D. Nicolás Calvo Quijano.

\section{BIBLIOGRÁFICAS}

AMORES, J. B. (2006). Historia de América. Barcelona, España: Editorial Ariel.

BLANCO, J. (enero - julio de 2005). Colombia multicultural. Historia del derecho a la inclusión. Informe final de investigación. Revista Diálogos de Saberes, 25, 84.

BLANCO, J. (Julio, Diciembre de 2007). De la Gran Colombia a la nueva granada, contexto histórico-político de la transición constitucional. En: Revista Prolegómenos Derechos y Valores No. 20. Centro de investigaciones Socio Jurídicas, Universidad Militar Nueva Granada, Facultad de Derecho., 20, 72.

BLANCO, J. \& CÁRDENAS, M. (2010). Historia y Administración del Estado en los primeros años de la república.Bogotá, Colombia: Universidad Militar Nueva Granada. Grupo IBAÑEZ editores.

BLANCO, J. \& CÁRDENAS, M. (2010-2). Historia y Administración del Estado Colombiano. Bogotá, Colombia: Universidad Militar Nueva Granada. Grupo IBAÑEZ editores.

HAGGIN, C. H. (1972). El Imperio Hispánico en América. Buenos Aires, Argentina; Solar Hachette.

HENAO, J. (2004). El Poder Municipal. (11 Ed.). Medellín, Colombia: Biblioteca Jurídica Diké.

HERNANDEZ, G. (2007). La real Audiencia. En: Colombia en la Historia. Tomo I. Villavicencio, Colombia: Corporación Universitaria del Meta.

HERVADA, J. (2000). Introducción al Derecho Natural. Bogotá, Colombia: Editorial Temis S.A. Instituto de humanidades Universidad de la Sabana.

LLAMAS, D. S. (1827). Comentario crítico, jurídico, literal, a las ochenta y tres Leyes de Toro. Tomo I. Madrid, España: Imprenta de Repullés, Plazuela del Angel.

MARTINEZ, A. (2008). La agenda de Colombia 1819-1831.Bucaramanga, Colombia Universidad Industrial de Santander.

MEDINA, A. (2002). Génesis del Derecho Administrativo en la Nueva Granada. Trabajo de grado para optar por el título de Abogado. Pontifica Universidad Javeriana Facultad de Ciencias Jurídicas. Bogotá, Colombia.

PACHECO, J., DE LA PUENTE, F. \& APEZECHEA, F. (1847). Los códigos Españoles, concordados y anotados. Tomo I. Madrid, España: imprenta de la publicidad.

POMBO, M. A., \& GUERRA, J. J. (1991). Constituciones de Colombia, Constitución del Estado de Cartagena de Indias. (2ra Ed.). Bogotá, Colombia.

QUINTERO, A. (1971). Lecciones de Historia de Colombia. La Colonia 1499- 1819. Volumen XVI. Bogota, Colombia; Biblioteca Banco Popular. 
RESTREPO, C. constituciones de Colombia. (4 Ed.). Tomo I. Bogotá, Colombia: Biblioteca Banco Popular,. Pág. 481.

SANCHEZ, I., DE LA ERA, A. \& DIAZ, C. (1992). Historia del Derecho Indiano. Editorial Mateus Cromos.

TASCON, T. E. (2000). Historia del Derecho Constitucional Colombiano,Pereira, Colombia: Litoalfa.

TUDELA, J. (1954). El legado de España a América. Madrid, España: Ediciones Pegaso.

\section{Técnicas}

AUDIENCIA Y CANCILLERÍA REAL DE SANTAFÉ EN EL NUEVO REINO DE GRANADA. En.

http://www.alcaldiabogota.gov.co/sisjur/ normas/Norma1.jsp? $\mathrm{i}=13661$

CONSTITUCIÓN DEL ESTADO DE ANTIOQUIA: SANCIONADA POR LOS REPRESENTANTES DE TODA LA PROVINCIA Y ACEPTADA POR EL PUEBLO EL 3 DE MAYO DEL AÑO DE 1812. p. 4 En. http:// www.cervantesvirtual.com/obra/constitucion- del-estado-de-antioquia-sancionada-porlos-representantes-de-toda-la-provincia-yaceptada-por-el-pueblo-el-3-de-mayo-del-anode-1812--0/

CONSULTOR DE LOS AYUNTAMIENTOS $Y$ DE LOS JUZGADOS MUNICIPALES. (1870,1945). periódico de administración y de justicia municipal. Madrid, España. En. http:// rebiun.absysnet.com/cgi-bin/rebiun/O7916/ ID1284d3bf/NT5

GARCÍA, M. (1954). Apuntes sobre Codificación y Costumbre en la Historia del Derecho Colombiano. En http://bibliotecadigital.icesi. edu.co/biblioteca_digital/handle/item/429.

GRAN ENCICLOPEDIA RIALP. Humanidades y Ciencia. Indias, Gobierno De. I. Consejo de Indias. En. http://www.canalsocial.net/ger/ ficha_GER.asp?id $=10230 \&$ cat $=$ politica

\section{LA CREACIÓN DEL VIRREINATO DE NUEVA} GRANADA. En. http/www.uc.cl/sw_educ/ historia/america/html/1_2_3.html

LLANO, R. (2002). Hechos y gentes de la primera república colombiana (1810-1816). Bogotá, Colombia. http://www.banrepcultural. org/blaavirtual/historia/primera/indice.htm 